\title{
Treatment of Severe Hypercholesterolemia in Apolipoprotein E-Deficient Mice by Bone Marrow Transplantation
}

\author{
William A. Boisvert, ${ }^{*}$ Jörg Spangenberg, ${ }^{*}$ and Linda K. Curtiss ${ }^{* \neq}$ \\ *Department of Immunology, IMM-17, ${ }^{\ddagger}$ Department of Vascular Biology, The Scripps Research Institute, La Jolla, California 92037
}

\begin{abstract}
Apo E, a key regulator of cholesterol-rich lipoprotein metabolism, is synthesized by numerous extrahepatic tissues. Although its synthesis in macrophages is documented, the contribution of macrophage-derived apo $\mathbf{E}$ to hepatic clearance of serum cholesterol is unknown. To address this issue bone marrow transplantation was performed on hypercholesterolemic apo E-deficient mice with either syngeneic apo Edeficient mouse bone marrow cells (E0-control) or wildtype mouse bone marrow cells expressing apo $\mathrm{E}$ (E0treated). E0-control and E0-treated mice were fed either a regular chow diet or an atherogenic diet (designated E0control-HF and E0-treated-HF). Serum cholesterol levels dropped dramatically in the E0-treated mice largely due to a reduction in their VLDL cholesterol. No changes were seen in the E0-control mice. After 4 wk serum cholesterol in E0-treated-HF mice was about four-fold lower compared to E0-control-HF animals. Moreover, the extent of atherosclerosis in the E0-treated-HF mice after 14-16 wk was greatly reduced. Wild-type apo $\mathbf{E}$ mRNA was detected in the liver, spleen, and brain of the E0-treated mice indicating that apo $\mathbf{E}$ gene transfer was successfully achieved through bone marrow transplantation. More importantly, the level of apo $\mathbf{E}$ expression was sufficient to reduce the severe hypercholesterolemia of the apo E-deficient mice fed either chow or atherogenic diets. (J. Clin. Invest. 1995. 96:11181124.) Key words: atherosclerosis • macrophages • atherogenic diet $\bullet$ reverse transcriptase-PCR $\cdot$ gene transfer
\end{abstract}

\section{Introduction}

Apo $\mathrm{E}$ is a constituent of cholesterol-rich plasma lipoproteins including hepatically derived VLDL and intestinally derived chylomicron remnants. Apo E mediates the binding of these

While this manuscript was being reviewed, similar results were reported by Linton, M.E., J. B. Atkinson, and S. Fazio 1995. Science (Wash. DC). 267:1034-1037. Both W. A. Boisvert and J. Spangenberg contributed equally to this work.

Address correspondence to Linda K. Curtiss, Department of Immunology, IMM-17, (Department of Vascular Biology), The Scripps Research Institute, 10666 North Torrey Pines Road, La Jolla, CA 92037. Phone: 619-554-8248; FAX: 619-554-6146.

Received for publication 3 January 1995 and accepted in revised form 4 May 1995.

The Journal of Clinical Investigation, Inc.

Volume 96, August 1995, 1118-1124 lipoproteins to hepatic LDL receptors (LDL-R) ${ }^{1}$ and the LDL$R$-related protein (LRP), thereby directing these lipoproteins to the only organ that can facilitate their removal from the body.

Although the liver is a major site of apo E synthesis, other tissues including brain, spleen, adrenal gland, lung, testis, and ovary synthesize this protein (1-3). Apo $E$ is synthesized by monocyte/macrophages $(4,5)$, but not by leukocytes (including lymphocytes and granulocytes) depleted of monocyte/macrophages (1). In tissues, apo $\mathrm{E}$ is detected in the cytoplasm of all tissue macrophages (including Kupffer cells, histiocytes, and lymph node macrophages) but not in other immune cells such as lymphoid cells of spleen and lymph nodes (6). Macrophage-derived apo $\mathrm{E}$ is postulated to be involved in immunoregulation (7), regeneration of peripheral nerves (8), and prevention of cholesteryl ester accumulation $(9,10)$. However, the contribution of macrophage apo $\mathrm{E}$ to hepatic removal of cholesterol-rich lipoproteins has been considered minimal. For example, it was estimated in liver transplant patients that extrahepatically derived apo E contributes $<10 \%$ to plasma levels of apo E (11).

Two groups of investigators independently reported the creation of apo E-deficient mice by gene targeting in embryonic stem cells $(12,13)$. These mice display severe hypercholesterolemia even on a low fat, low cholesterol chow diet. Fast protein liquid chromatography (FPLC) profiles of their plasma demonstrate elevated levels of cholesterol in VLDL, intermediate density lipoprotein (IDL) and, to a lesser degree, LDL. This is accompanied by a lower HDL cholesterol $(12,13)$. This lipoprotein phenotype is even more pronounced when the mice are fed an atherogenic diet. Furthermore, in contrast to wild-type mice, which are resistant to atherosclerosis, apo E-deficient mice develop the early fatty streak lesions of atherosclerosis within a few months of birth $(12,13)$.

There are differences in lipoprotein metabolism between humans and mice. In humans, apo $B$ is a ligand for the LDL-R along with apo $\mathrm{E}$, albeit with lower affinity than apo $\mathrm{E}$. This hepatic apo B is secreted as a full length protein (apo B100) that contains the LDL-R-binding domain. In mice a large portion of the hepatically derived apo B is truncated (apo B48) and does not contain the LDL-R-binding domain. Whereas wild-type mouse VLDL and IDL contain equal proportions of apo B48 and apo B100, VLDL and IDL from apo E-deficient mice contain $\sim 20$-fold higher apo B48 than apo B100 (13). This increase reflects the impaired apo E-dependent clearance of these VLDL remnants. With such a compromised compensatory

1. Abbreviations used in this paper: FPLC, fast protein liquid chromatography; IDL, intermediate density lipoprotein; LDL-R, LDL receptor; LRP, LDL-R-related protein. 
mechanism for hepatic clearance of VLDL and IDL due to the low levels of apo B100, apo $\mathrm{E}$ is requisite in mice for catabolizing these lipoproteins. This is evidenced by the severe hypercholesterolemia with accumulation of VLDL and IDL cholesterol seen in apo E-deficient mice. Additionally, LRP binds apo $\mathrm{E}$ but not apo B (14), thereby compromising the LRP-mediated hepatic cholesterol clearance in these apo E-deficient mice as well.

By transplanting wild-type bone marrow cells into irradiated apo E-deficient mice, we created mice whose sole source of apo $\mathrm{E}$ was bone marrow-derived macrophages. These mice served as models to study the contribution of macrophage-derived apo $\mathrm{E}$ to the hepatic clearance of cholesterol. Our findings indicate that bone marrow transplantation after total body irradiation successfully transferred the apo $E$ gene into the apo $\mathrm{E}$-deficient mice and that apo $\mathrm{E}$ resulting from the transplanted normal bone marrow-derived macrophages reversed the hypercholesterolemia normally seen in these apo E-deficient mice when they were fed a chow diet. On an atherogenic diet both the severe hypercholesterolemia and the extent of atherosclerosis in the apo E-deficient mice were drastically reduced by transplantation of wild-type bone marrow.

\section{Methods}

Animals. C57BL/6J apo E-deficient mice were obtained from The Jackson Laboratories (Bar Harbor, ME). Wild-type C57BL/6J mice expressing the rare Ly5.2 allele of the common leukocyte antigen, CD45, were from the Rodent Breeding Facility of The Scripps Research Institute (La Jolla, CA). All mice were weaned at 4 wk of age and were fed ad lib. either a standard chow diet (Diet No. 5015; Harlan Teklad, Madison, WI) or an atherogenic diet (Diet No. TD88051; Harlan Teklad) containing $15.8 \%(\mathrm{wt} / \mathrm{wt})$ fat, $1.25 \%(\mathrm{wt} / \mathrm{wt})$ cholesterol, and $0.5 \%(\mathrm{wt} / \mathrm{wt}$ ) sodium cholate. The animals were housed in autoclaved filter top cages with autoclaved water and kept on a 12-h light-dark cycle. Blood was obtained after a 4-h fast by retroorbital puncture under Metofane-induced anesthesia. Serum was obtained by centrifuging the blood samples at $3,000 \mathrm{~g}$ for $30 \mathrm{~min}$ at $4^{\circ} \mathrm{C}$.

Irradiation and bone marrow transplantation. 14 6-wk-old male apo E-deficient mice were subjected to 1,000 rads of total body irradiation to eliminate endogenous bone marrow stem cells and most of the bone marrow-derived cells, including macrophages. Bone marrow cells for transplantation into the irradiated mice were prepared by flushing both femurs of male donor mice. The donor mice were either C57BL/ 6J apo E-deficient mice, which expressed the common CD45Ly5.1 alloantigen, or C57BL/6J wild-type mice, which expressed the rare CD45Ly5.2 alloantigen. Donor cells were washed and suspended in Dulbecco's minimal essential medium with 5\% FBS and $1 \mathrm{mM}$ Hepes. After counting the cells were concentrated to $4 \times 10^{6}$ cells $/ \mathrm{ml} .3 \mathrm{~h}$ after irradiation the mice were injected in the tail vein with $2 \times 10^{6}$ bone marrow cells. To control for the rigors of irradiation, six of the mice received bone marrow cells from apo E-deficient mice (henceforth referred to as E0-control mice). All other mice received the wild-type C57BL/6J, CD45Ly5.2-expressing bone marrow cells (henceforth referred to as E0-treated mice). Two of the chow-fed mice (139 and 140) were designated as E0-controls and four of the chow-fed mice (141144) were designated as E0-treated mice. Of the eight mice fed the atherogenic diet, four were designated as E0-control-HF mice and the other four as E0-treated-HF mice.

Serum cholesterol and lipoprotein analyses. Total serum cholesterol was measured by a fluorometric method using an enzymatic kit from Boehringer Mannheim Corp. (Indianapolis, IN) according to manufacturer's protocol. Serum samples from all mice were diluted according to their cholesterol content to fit into the linear portion of the standard curve. Inter- and intraassay coefficients of variance were $<5 \%$.
Serum lipoprotein patterns were analyzed by agarose gel electrophoresis using premade gels from Ciba Corning Diagnostics Corp. (Palo Alto, CA). After loading $1 \mu \mathrm{l}$ of serum, the gels were run at $9 \mathrm{~V} / \mathrm{cm}$ for $35 \mathrm{~min}$ in Universal buffer (Ciba Corning Diagnostics Corp.), stained with Oil Fat 7B (Ciba Corning Diagnostics Corp.), and photographed.

Lipoprotein fractionation was achieved by FPLC using an FPLC system from Pharmacia LKB Biotechnology Inc. (Piscataway, NJ). Filtered serum $(0.1 \mathrm{ml})$ was applied to a $1 \times 30 \mathrm{~cm}$ Superose 6 column (Pharmacia LXB Biotechnology Inc.) and eluted with $10 \mathrm{mM}$ Tris-HCI buffer, pH 7.4, containing $0.15 \mathrm{M} \mathrm{NaCI}$ and $0.01 \%$ EDTA. Fractions $(40 \times 0.5 \mathrm{ml})$ were collected and assayed for their total cholesterol content.

Flow cytometry. Mouse blood $(0.2 \mathrm{ml})$ was washed twice in PBS, pH 7.4, containing 1\% FBS (wash buffer). The red blood cells were lysed by adding $1 \mathrm{ml}$ of $\mathrm{NH}_{4} \mathrm{CI}, \mathrm{pH} 7.2$, and incubating the cells on ice for $10 \mathrm{~min}$. The remaining leukocytes were washed and resuspended in $0.1 \mathrm{ml}$ of wash buffer. The cells were stained at $4^{\circ} \mathrm{C}$ for $40 \mathrm{~min}$ in the dark with a 1:1,000 dilution of a biotinylated monoclonal antibody specific for the Ly5.2 allele of the mouse CD45 antigen. The cells were washed three times in wash buffer and incubated under the same condition with FITC-conjugated streptavidin (PharMingen, San Diego, CA). The cells were washed two times, resuspended in $0.5 \mathrm{ml}$ of wash buffer and analyzed on a FACScan $\circledast$, flow cytometer (Becton Dickinson and Co., San Jose, CA).

Qualitative reverse transcriptase-PCR. Total RNA was isolated from liver, spleen, and brain of wild-type, E0-control (139) and E0treated (141) mice by the method of Chomczynski and Sacchi (15) after homogenization of the tissues. Reverse transcription was performed in a $0.02-\mathrm{ml}$ reaction volume with $2 \mu \mathrm{g}$ of total RNA, $100 \mathrm{ng}$ of random primer (GIBCO BRL, Gaithersburg, MD), $0.5 \mathrm{mM}$ mixed deoxynucleotides (Boehringer Mannheim Corp.), $40 \mathrm{U}$ of RNasin RNase inhibitor (Promega Corp., Madison, WI), and $200 \mathrm{U}$ of Superscript II reverse transcriptase (GIBCO BRL). The mixture was incubated at $37^{\circ} \mathrm{C}$ for $50 \mathrm{~min}, 42^{\circ} \mathrm{C}$ for $20 \mathrm{~min}$, and $90^{\circ} \mathrm{C}$ for $10 \mathrm{~min}$ to inactivate the enzyme. The $0.05 \mathrm{ml} \mathrm{PCR}$ reactions contained $2 \mu \mathrm{l}$ of cDNA together with $16.6 \mathrm{mM}\left(\mathrm{NH}_{4}\right)_{2} \mathrm{SO}_{4}, 6.7 \mathrm{mM} \mathrm{MgCl} 267 \mathrm{mM}$ Tris-HCl, $\mathrm{pH} 8.8$, $0.17 \mathrm{mg} / \mathrm{ml}$ bovine serum albumin, $5 \%$ glycerol (all chemicals from Sigma Chemical Co., St. Louis, MO), $1 \mathrm{mM}$ mixed deoxynucleotide (Boehringer Mannheim Corp.), $25 \mathrm{pmol} /$ reaction each of downstream and upstream primers and $2.5 \mathrm{U}$ of Taq polymerase (Stratagene Inc., La Jolla, CA). After heating the samples for $5 \mathrm{~min}$ at $94^{\circ} \mathrm{C}$, amplification conditions for 35 cycles were as follows: $1 \mathrm{~min}$ at $94^{\circ} \mathrm{C}$ for denaturation, $1 \mathrm{~min}$ at $65^{\circ} \mathrm{C}$ for primer annealing, and $2 \mathrm{~min}$ at $72^{\circ} \mathrm{C}$ for polymerase extension. To extend the PCR products, the samples were incubated for $7 \mathrm{~min}$ at $72^{\circ} \mathrm{C}$. PCR products were separated on a $4 \%$ NuSieve gel (FMC Corp. BioProducts, Rockland, ME) before they were stained with ethidium bromide and photographed.

Preparation and examination of aortae for atherosclerosis. To qualitatively assess the extent of atherosclerosis throughout the entire length of the aorta from the aortic valve to the iliac bifurcation, E0-control-HF and E0-treated-HF mice were killed 14-16 wk after bone marrow transplantation. The tissues were prepared as described (16). Briefly, the blood was removed by perfusion with PBS ( $\mathrm{pH} 7.4$ ) into the left ventricle via a cannula. An incision was made in the inferior vena cava to clear the perfusate. The tissues were fixed by continued perfusion with formal-sucrose (4\% paraformaldehyde and 5\% sucrose, pH 7.4). The aortae were revealed by microscopic dissection, their adventitia cleaned and while attached, opened longitudinally from the common iliac arteries to the aortic valve. Then the aortae were detached and pinned flat onto the smooth black wax surface of a dissecting pan with $0.2-\mathrm{mm}$ diameter stainless steel pins before they were stained with Sudan IV. Stained fatty streak lesions appeared bright red.

Statistics. Student's $t$ test was performed on the serum cholesterol data between the E0-control-HF and E0-treated-HF mice. The results are given as mean \pm standard deviation. Sigma Plot (version 2.0; Jandel Corp., San Rafael, CA) was used for data analysis. 


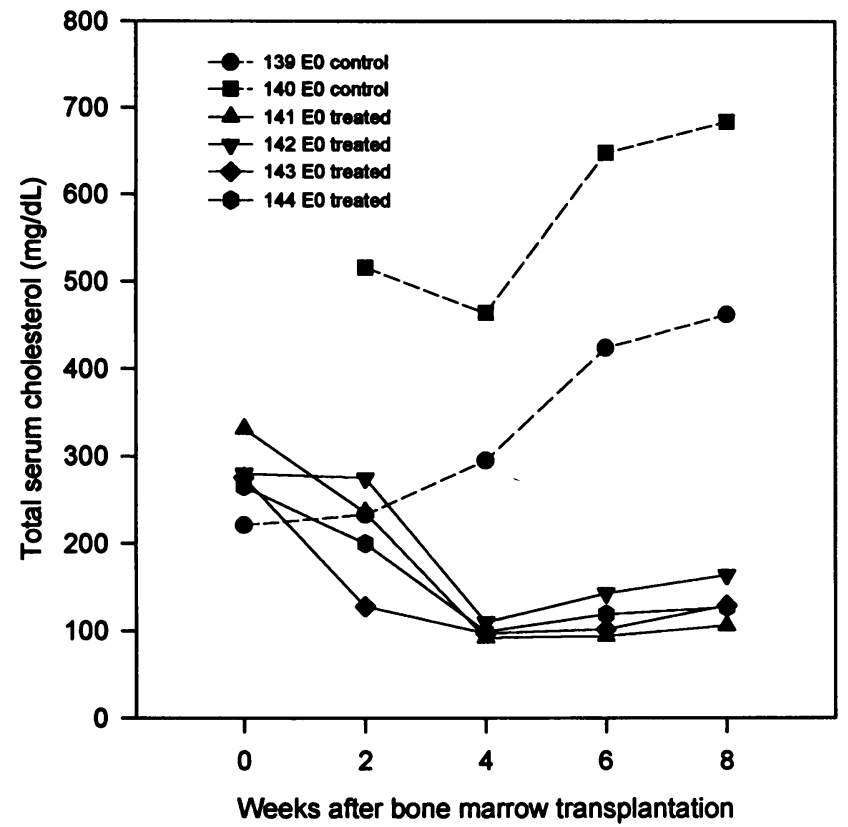

Figure 1. Total serum cholesterol levels in individual E0-control (animals 139 and 140) and E0-treated mice (141-144) before and after bone marrow transplantation. Cholesterol was measured in the serum using an enzymatic kit as described in Methods. The inter- and intraassay coefficients of variance were $<5 \%$. Blood was not obtained from mouse 140 before irradiation.

\section{Results}

Mice fed standard chow diet. The six chow-fed apo E-deficient mice shown in Fig. 1 were from the same litter. They had similar total serum cholesterol levels before irradiation and bone marrow transplantation (range: $221-331 \mathrm{mg} / \mathrm{dl}$; mean $\pm \mathrm{SD}$ $275 \pm 39 \mathrm{mg} / \mathrm{dl}$ ). By $4 \mathrm{wk}$, serum cholesterol dropped in the E0-treated mice (mean \pm SD $100 \pm 8 \mathrm{mg} / \mathrm{dl}$ ), while it remained high in the E0-control mice ( 295 and $464 \mathrm{mg} / \mathrm{dl}$ ). By $8 \mathrm{wk}$ after transplantation, serum cholesterol in the E0-control mice was 462 and $684 \mathrm{mg} / \mathrm{dl}$, whereas the mean serum cholesterol in the E0-treated mice was down to $131 \pm 24 \mathrm{mg} / \mathrm{dl}$.

Repopulation by the transplanted bone marrow cells was monitored at $5 \mathrm{wk}$ in the peripheral blood leukocytes of E0control and E0-treated mice. To document repopulation we used donor wild-type mice that expressed an altered version (Ly5.2) of the common leukocyte antigen, CD45. The CD45Ly5.2 antigen was identified by flow cytometry with a biotinylated monoclonal antibody and FITC-conjugated streptavidin. Because the apo E-deficient mice express the CD45Ly5.1 allele, the leukocytes from the E0-control mouse were not stained with the CD45Ly5.2 alloantigen-specific monoclonal antibody (Fig. 2, left). In contrast, the leukocytes of an E0-treated mouse expressed this wild-type donor cell alloantigen indicating repopulation by the donor bone marrow cells (Fig. 2, right).

The serum lipoprotein phenotypes of the chow-fed mice were qualitatively analyzed by agarose gel electrophoresis and the gels were stained with Oil Fat 7B to reveal the lipoproteins (Fig. 3). Before bone marrow transplantation similar patterns in lipoprotein distribution were observed in all apo E-deficient mice. The patterns were typified by a large accumulation of $\beta$ - and pre- $\beta$-migrating VLDL, IDL, and LDL, and diminished

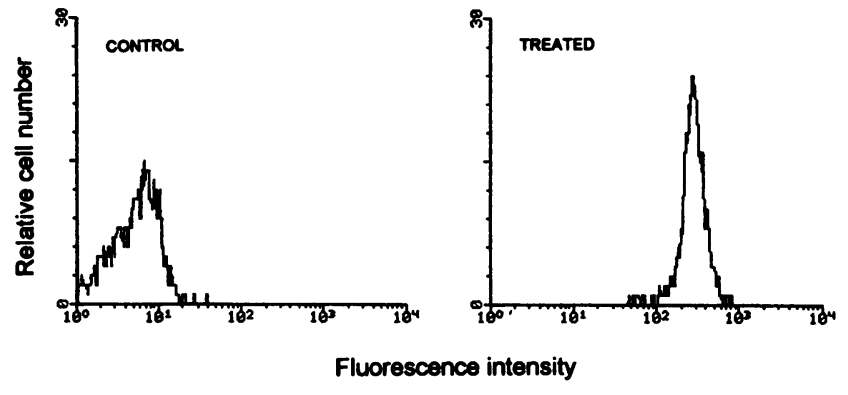

Figure 2. Representative FACS ${ }^{\circledR}$ analysis of peripheral blood leukocytes from an E0-control mouse (139) and an E0-treated mouse (142) for the presence of the CD45Ly5.2 alloantigen. The isolated leukocytes were reacted with biotinylated CD45Ly5.2-specific monoclonal antibody and FITC-conjugated streptavidin and were analyzed on a FACScan ${ }^{\circledR}$ flow cytometer to monitor repopulation in the transplanted mice. The donor mice expressed the Ly5.2 allele of the leukocyte common antigen, CD45; whereas the apo E-deficient mice expressed the Ly5.1 allele. Leukocytes from E0-control mice showed only background fluorescence, whereas essentially all of the leukocytes from the E0-treated mice were bound by the Ly5.2-specific antibody.

$\alpha$-migrating HDL. Little change was seen in this phenotype at 2 wk. However, after 8 wk the VLDL/LDL lipoproteins decreased in the E0-treated mice (141-144), but remained high in the E0-control mice (139, and 140). The sera from all the E0-treated mice had increased HDL as well.

Lipoproteins also were analyzed by FPLC 8 wk after bone

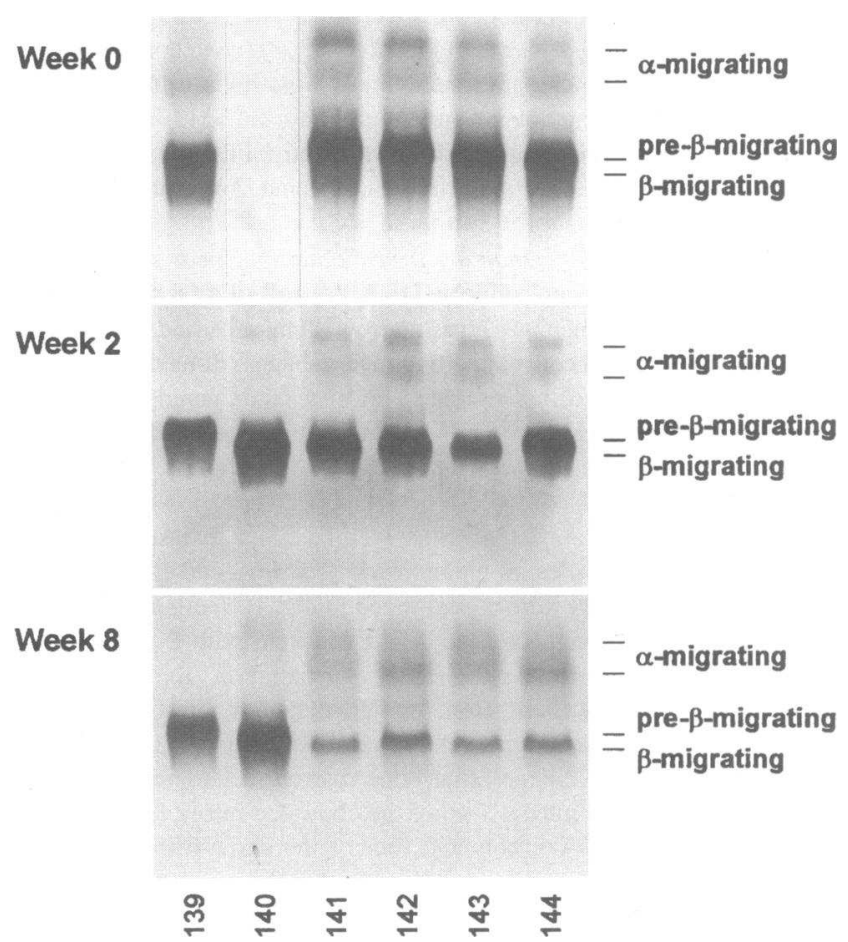

Figure 3. Agarose gel electrophoresis of serum lipoproteins from individual E0-control mice (139 and 140) and E0-treated mice (141-144). Migration patterns of HDL ( $\alpha$-migrating), VLDL (pre- $\beta$-migrating), and LDL ( $\beta$-migrating) are indicated. Shown on the gels are sera from individual animals before (wk 0 ) and after (wk 2 and 8 ) bone marrow transplantation. 


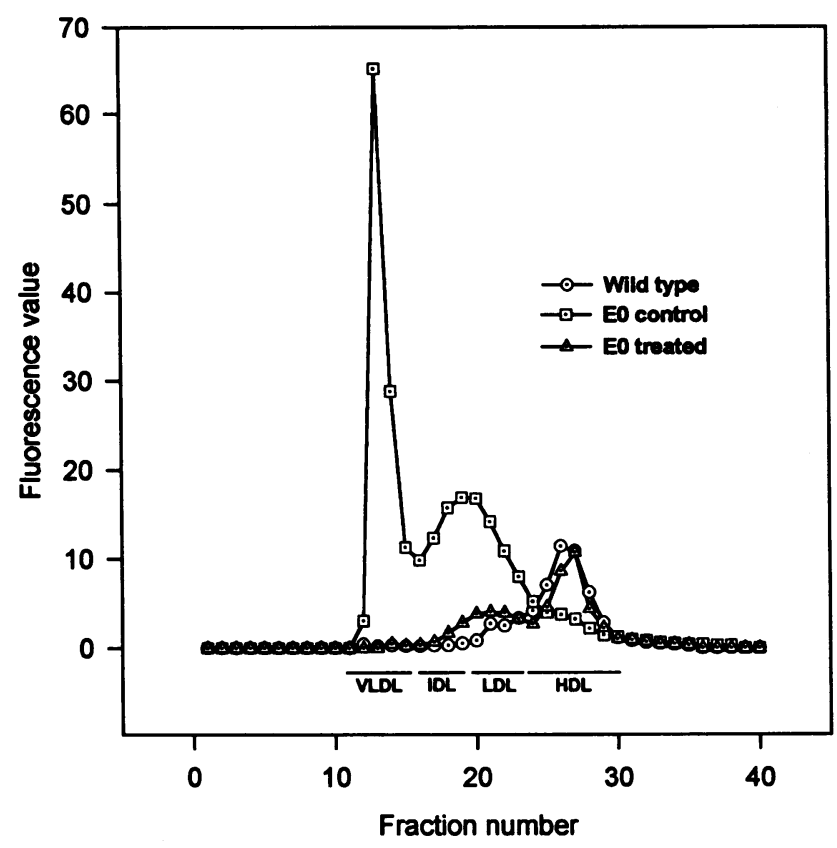

Figure 4. FPLC profiles of lipoproteins from wild-type, E0-control, and E0-treated mice 8 wk after transplantation. For this analysis, serum samples were pooled in equal proportions from four wild-type mice, two E0-control mice, or four E0-treated mice. Cholesterol was measured in each $0.5-\mathrm{ml}$ fraction with the fluorometric enzymatic assay as described in Methods. The fluorescence values approximate the relative content of cholesterol in each fraction. The elution patterns of isolated human lipoproteins are indicated.

marrow transplantation (Fig. 4). The wild-type phenotype was characterized by a major HDL cholesterol peak and undetectable levels of VLDL and IDL cholesterol. The profile observed in the E0-treated mice was similar to that of the wild-type, with only a small increase in IDL and LDL cholesterol. HDL was the predominant cholesterol-containing lipoprotein. In contrast, homologous E0-control mice displayed high levels of VLDL and IDL cholesterol and reduced levels of HDL cholesterol. This phenotype was indistinguishable from that of nonbone marrow transplanted apo E-deficient mice.

To qualitatively monitor the expression of apo $\mathrm{E}$ in the liver, spleen, and brain of the transplanted mice, apo E mRNA was identified by reverse transcriptase-PCR. Piedrahita et al. (17) created the original mutant apo $\mathrm{E}$ gene by replacing a 131 base fragment of exon 3 plus a portion of intron 3 (an XhoI/BamHI fragment) with the neomycin phosphotransferase (neo) gene. To detect both the defective neo-apo E mRNA (generated from transcription by the promoter in the neo-containing plasmid) and the normal apo E mRNA, two sets of primers were used (Fig. $5 \mathrm{~B}$ ). The downstream primer (5'-CTGGCGATGCATGTCTTCCAC- $3^{\prime}$ ) was common for both mRNAs and bound near the $3^{\prime}$ end of exon 4 (primer 3 ). The upstream primer for detection of both mutant and normal mRNAs ( $5^{\prime}$-TGGGCCAGAGCACAGAGGAG-3') bound near the $5^{\prime}$ end of exon 4 (primer 2). The other upstream primer for detection of normal mRNA ( 5 '-TCTGACCAGGTCCAGGAAGAG-3') bound the region in exon 3 replaced by the neo gene in the mutant mRNA (primer 1). Primers $2 / 3$ yielded a 449-bp product with both mutant and wild-type apo E mRNAs, whereas primers $1 / 3$ yielded a 686-bp product only with wild-type apo E mRNA (Fig. $5 B$ ).

8 wk after transplantation, both mutant and wild-type apo E mRNAs were present in the tissues of all mice, as seen by a single band of the predicted size using primers $2 / 3$ (Fig. $5 A$ ). Wild-type apo $\mathrm{E}$ mRNAs were detected only in the tissues of wild-type and E0-treated mice, as seen by the predicted bands using primers 1/3. Because wild-type apo E mRNA was detected in the liver, spleen, and brain of the E0-treated mice 8 wk after irradiation, at least these three tissues had been repopulated by cells derived from the wild-type donor bone marrow.

Mice fed an atherogenic diet. Apo E-deficient mice fed an atherogenic diet containing $1.25 \% \mathrm{wt} / \mathrm{wt}$ cholesterol developed severe hypercholesterolemia within 2-3 wk (13). To assess the effect of bone marrow transplantation on a more severe hypercholesterolemia phenotype, eight mice were put on a high fat diet $1 \mathrm{wk}$ after bone marrow transplantation. These mice were monitored for their total serum cholesterol levels and examined visually for atherosclerotic lesion formation. Although serum cholesterol levels were similar between the E0-control$\mathrm{HF}$ and $\mathrm{E} 0$-treated-HF animals before bone marrow transplantation, significant differences in mean cholesterol levels between the two groups were apparent after 2 wk (Fig. 6). From 4 to $8 \mathrm{wk}$ after transplantation cholesterol levels stabilized at 4,500$5,000 \mathrm{mg} / \mathrm{dl}$ in the E0-control mice and at $1,100-1,300 \mathrm{mg} /$ $\mathrm{dl}$ in the E0-treated-HF mice. This represented a statistically significant $(P<0.003)$ mean difference of about four-fold between mice receiving apo $\mathrm{E}$-expressing versus apo $\mathrm{E}$-deficient bone marrow myeloid stem cells.

To compare the extent of atherosclerotic lesion formation in the two groups, the mice were maintained on the atherogenic diet and killed between 14 and 16 wk after bone marrow transplantation. The aorta extending from the aortic valve to the common iliac bifurcation was dissected out and pinned flat to reveal the lesions. The aortae were stained with Sudan IV to identify the red-stained raised fatty lesions. Visual inspection of the aortae revealed that the lesions were more extensive in the E0-control-HF mice compared to E0-treated-HF mice, especially around the thoracic and abdominal aorta regions (Fig. 7). Although only one aorta from each group is shown, preparations from other animals showed similar differences in lesion formation between the two groups.

\section{Discussion}

This study demonstrated that repopulation of chow-fed apo Edeficient mice with bone marrow cells from apo E-expressing wild-type mice reversed their hypercholesterolemia and qualitatively converted their lipoprotein phenotype to that of wild-type mice. Because complete repopulation of the peripheral blood leukocytes of the apo E-deficient mice occurred within $5 \mathrm{wk}$ of transplantation, and because only the myeloid stem cells give rise to monocytes within the peripheral blood leukocytes that can eventually synthesize apo $E(1,6)$, the likely source of apo $\mathrm{E}$ in the E0-treated mice was the transplanted wild-type bone marrow-derived macrophages.

In human bone marrow transplant recipients, blood macrophages are almost entirely of donor origin as early as $41 \mathrm{~d}$ after transplantation, and exhibit normal function (18). Furthermore, hepatic and alveolar macrophages originate from donor bone marrow cells (19-26). Most tissue macrophage turnover occurs between 4 and $15 \mathrm{~d}$ (27). Thus, the detection of the CD45Ly5.2 

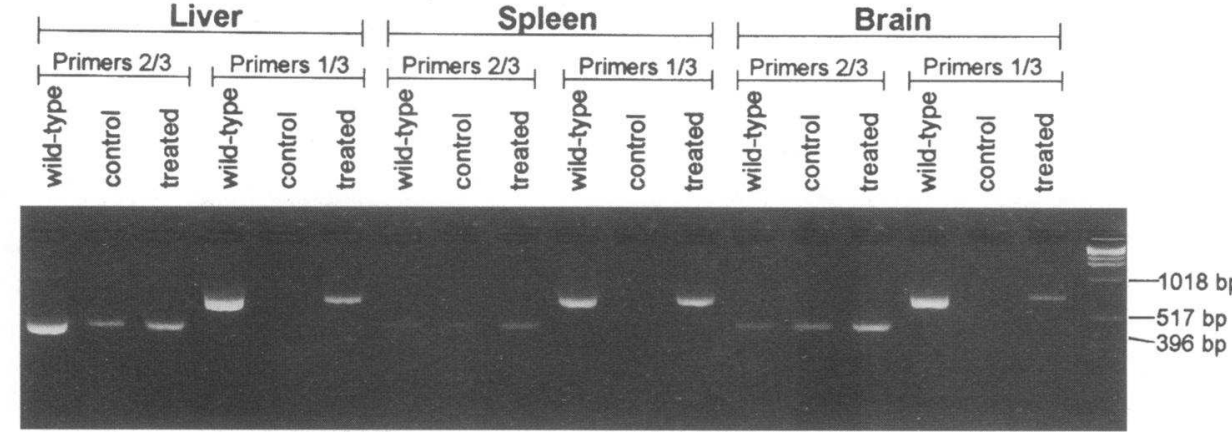

B

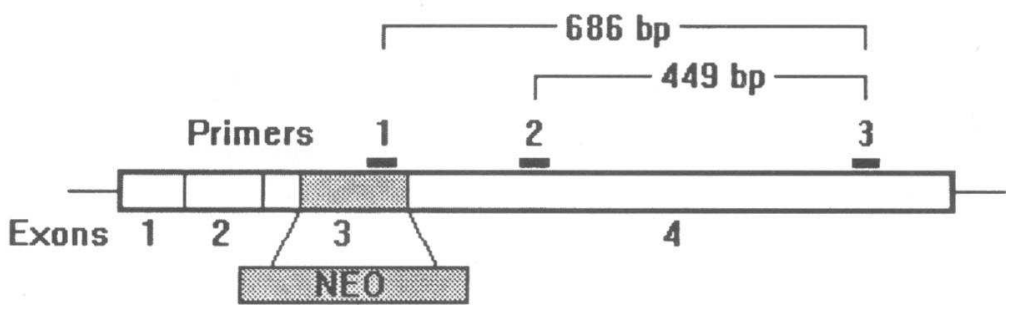

Figure 5. (A) Qualitative reverse transcriptase-PCR analysis of total RNA from selected mouse tissues. Total RNA of liver, spleen, and brain of a wild-type mouse, an E0control mouse (139), and an E0treated mouse (141) was analyzed for the presence of wild-type apo E mRNA with primers $2 / 3$ and for mutant neo-apo E mRNA with primers $1 / 3$ as described in Methods. $(B)$ Map of the murine apo $E$ gene. The primers are indicated above the box and the exons below. Primers 2 and 3 bound within exon 4, thereby yielding a PCR product of $449 \mathrm{bp}$ with both the wild-type and the mutant apo $\mathrm{E}$ mRNAs. Primer 1 bound within the exon 3 that is replaced by the neo fragment in the apo E-deficient mice (15). Amplifications using primers $1 / 3$ yielded a 686 bp PCR product with the wildtype apo E mRNA, but not the mutant apo E mRNA. leukocyte alloantigen in the circulating leukocytes and the detection of normal apo E mRNA in the liver, spleen, and brain of E0-treated but not the E0-control mice, provided compelling evidence that the macrophages of these tissues were of donor origin.

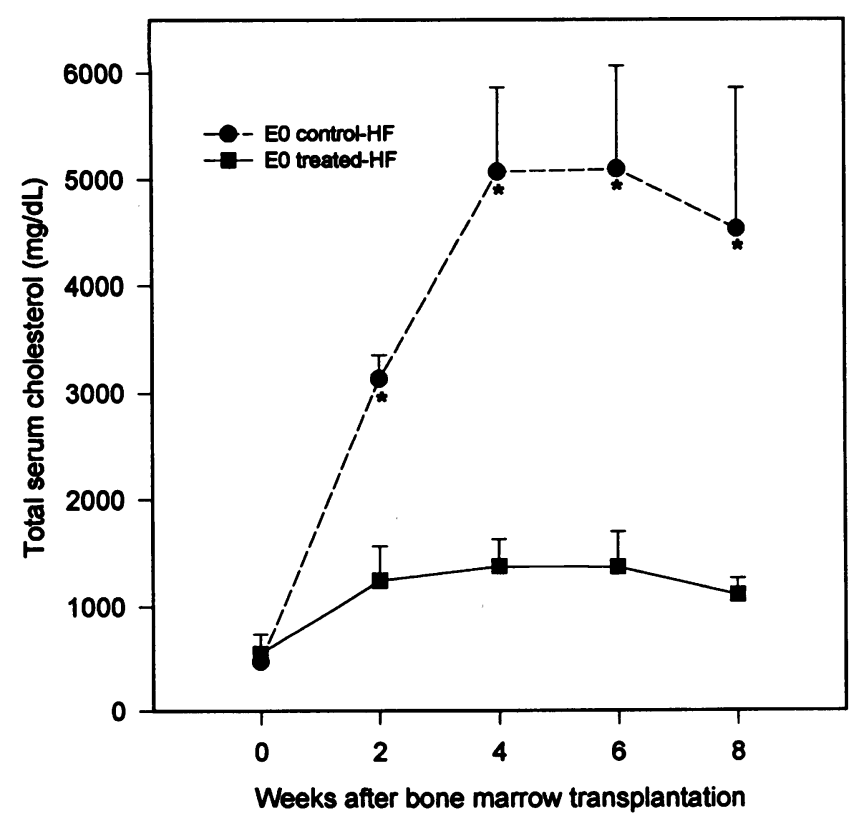

Figure 6. Total serum cholesterol levels of four E0-control-HF mice and four E0-treated-HF mice before and after bone marrow transplantation. All animals were started on the high fat diet 1 wk after bone marrow transplantation. Cholesterol was measured enzymatically as described in Methods. Values presented are mean \pm SD of individual animals. E0-control-HF values marked with an asterisk were significantly different from their corresponding E0-treated-HF values (all with $P$ $<0.003)$.
The total amount of macrophage-derived apo $\mathrm{E}$ in the body is unknown. A study of apo E mRNA expression by rat Kupffer cells indicated that Kupffer cell-derived apo E mRNA is $<1 \%$ of the total apo E mRNA of hepatocytes (28). In mice, Kupffer cells account for $\sim 20 \%$ of all macrophages in the body (29). If the synthesis of apo $\mathrm{E}$ by all macrophages is similar to that of Kupffer cells, total contribution by the entire macrophage population to circulating apo E should be $<5 \%$ of that of the hepatocytes. If so, the reduction in hypercholesterolemia seen in the E0-treated mice suggests that only small amounts of apo $\mathrm{E}$ were required for hepatic clearance of VLDL and IDL cholesterol. Furthermore, because serum levels of apo $E$ in the E0-treated mice (estimated by Coomassie staining and Western blotting of SDS-PAGE-separated proteins) were undetectable and therefore probably $<10 \%$ of the circulating levels of wildtype mice, the nearly normal hepatic uptake of cholesterol seen in the E0-treated mice may not be dependent on apo E that circulates in association with lipoproteins. Recent evidence suggests that heparan sulfate proteoglycans and LRP in the space of Disse play a key role in remnant lipoprotein uptake by the liver (30). If, as suggested by the reverse transcriptase-PCR data, the livers of the E0-treated mice contained apo E mRNA, locally produced apo E may be secreted by the Kupffer cells, promptly bound to cell surface proteoglycans, lipases, and/or phospholipids where it then becomes associated with cholesterol-rich lipoproteins that are immediately internalized by LRP for catabolism within hepatocytes. Thus, most of the hepatically derived apo $\mathrm{E}$ may remain in the space of Disse and not be present on circulating lipoproteins. It also is feasible that circulating lipoproteins containing apo $\mathrm{E}$ in the $\mathrm{E} 0$-treated mice are cleared very quickly by the liver, which could render the plasma apo $E$ undetectable as well using standard methods. The degree of apo E synthesis within the liver and its utilization in the E0treated mice are being investigated.

The reduction in HDL cholesterol seen in the apo E-defi- 

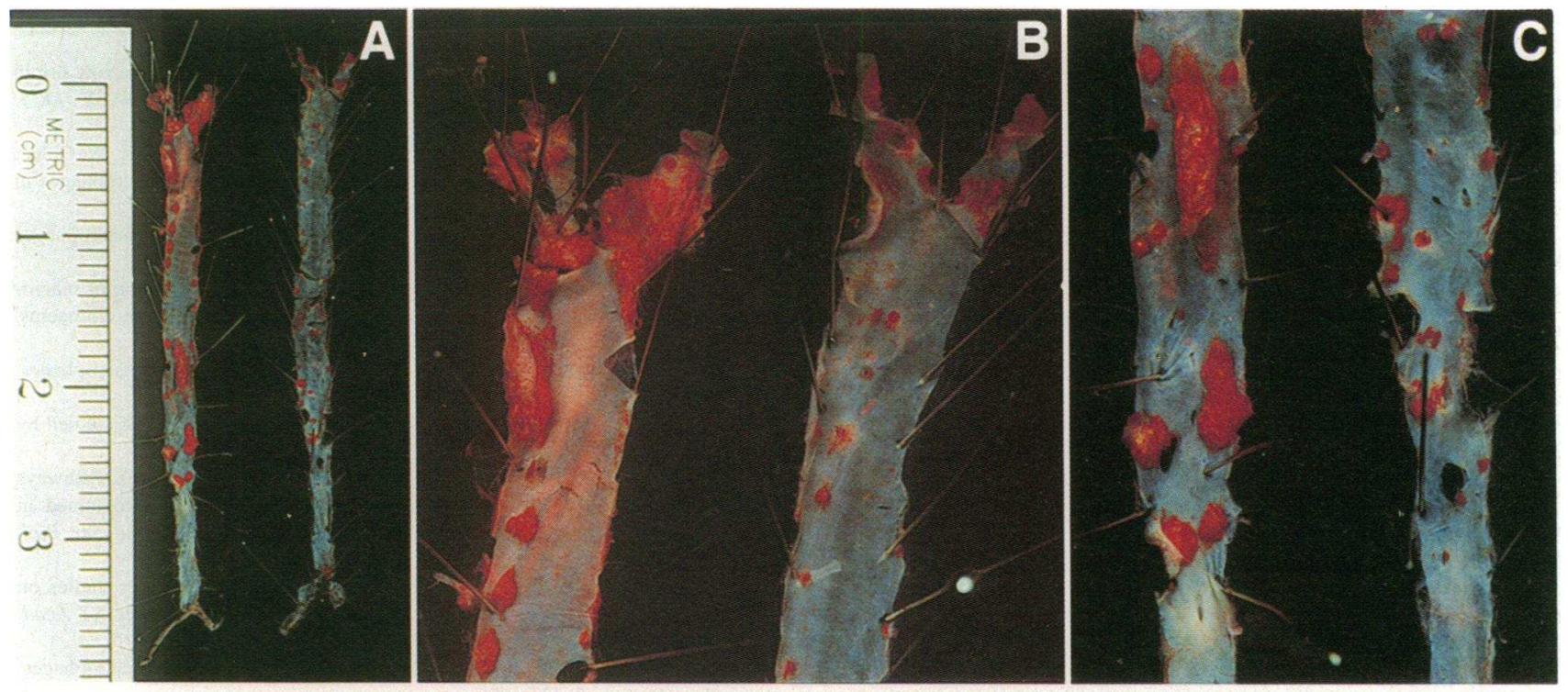

Figure 7. En face color photographs of the dissected and Sudan IV-stained aortae of an E0-control-HF mouse and an E0-treated-HF mouse. The animals were killed $16 \mathrm{wk}$ after bone marrow transplantation when they had been on the high fat diet for $15 \mathrm{wk}$. $A$ shows the aortae of an E0control-HF mouse on the left and an E0-treated-HF mouse on the right. $B$ and $C$ are close-ups of the thoracic and abdominal regions, respectively, of the aortae shown in $A$. A visual comparison of the two aortae suggests a significant difference in the extent of lesion formation in the two groups of fat-fed animals.

cient mice has been reported by other investigators $(12,13)$. The apparent increase in HDL cholesterol in our E0-treated mice to levels similar to those of wild-type mice implies that apo E may be required for normal metabolism of HDL cholesterol. However, the mechanism involved in this phenomenon is unknown. According to Zhang et al. (13), despite similarities in apo AI levels in the plasma of wild-type and apo E-deficient mice, HDL cholesterol in the apo E-deficient mice is half that of the wild-type mice. This apparent difference may be attributed to utilization of apo AI for structural components of VLDL and IDL that could lead to a shortage of apo AI for assembly of HDL (13). If so, it is plausible that more apo AI could have been available for HDL assembly in our E0-treated mice because of the sharp reduction in VLDL and IDL, and this resulted in higher HDL levels. Clearly, more studies are needed to understand the mechanism behind this observation.

The fourfold reduction in serum cholesterol in the E0treated-HF mice compared to E0-control-HF animals clearly shows that wild-type bone marrow-containing cells capable of expressing apo $\mathrm{E}$ were effective in protecting apo $\mathrm{E}$-deficient animals from the severe hypercholesterolemia caused by feeding an atherogenic diet. This protective effect was convincingly demonstrated by the reduced atherosclerotic lesion areas grossly observed in the aortae of the E0-treated mice compared to their control counterparts.

Although cholesterol levels of the animals in this study were monitored for only $8 \mathrm{wk}$ after transplantation, the results suggest that permanent transfer of the apo $\mathrm{E}$ gene was accomplished with bone marrow transplantation and that this gene transfer can correct the severe hypercholesterolemia phenotype associated with apo E deficiency. Furthermore, the data suggest that bone marrow transplantation may permanently treat the hypercholesterolemia that leads to atherosclerosis and cardiovascular disease in apo E-deficient animals. A more quantitative study of the effect of this treatment on arterial lesion formation in apo $\mathrm{E}$-deficient mice is being actively pursued.

\section{Acknowledgments}

The authors thank Dr. Charles Surh for assisting in bone marrow transplantation and for providing the CD45Ly5.2 antibody, Dr. Graham Parry for the wild-type mouse RNA, and Dr. Rajendra K. Tangirala, and Florence Casanada for their help in mouse aorta preparations. We are grateful to our colleagues in the laboratory for their helpful discussions and Anna Meyers for her help in preparing the manuscript.

This work was supported by National Institutes of Health (NIH) Grant HL-35297 to L. K. Curtiss. J. Spangenberg is supported by a fellowship from the California Affiliate of the American Heart Association and W. A. Boisvert by NIH Training Grant AI-07244.

\section{References}

1. Zannis, V. J., F. S. Cole, C. L. Jackson, D. M. Kurnit, and S. K. Karathanasis. 1985. Distribution of apolipoprotein A-I, C-II, C-III and E mRNA in fetal human tissues. Biochemistry. 24:4450-4455.

2. Williams, D. L., P. A. Dawson, T. C. Newman, and L. L. Rudel. 1985. Apolipoprotein E synthesis in peripheral tissues of nonhuman primates. J. Biol. Chem. 260:2444-2451.

3. Driscoll, D. M., and G. S. Getz. 1984. Extrahepatic synthesis of apolipoprotein E. J. Lipid Res. 25:1368-1379.

4. Basu, S. K., M. S. Brown, Y. K. Ho, R. J. Havel, and J. L. Goldstein. 1981. Mouse macrophages synthesize and secrete a protein resembling apolipoprotein $\mathrm{E}$ Proc. Natl. Acad. Sci. 78:7545-7549.

5. Basu, S. K., Y. K. Ho, M. S. Brown, D. W. Bilheimer, R. G. W. Anderson, and J. L. Goldstein. 1982. Biochemical and genetic studies of the apoprotein E secreted by mouse macrophages and human monocytes. J. Biol. Chem. 257:97889795.

6. Lin, C.-T., Y. Xu, J.-Y. Wu, and L. Chan. 1986. Immunoreactive apolipoprotein $\mathrm{E}$ is a widely distributed cellular protein. Immunohistochemical localization of apolipoprotein $\mathrm{E}$ in baboon tissues. J. Clin. Invest. 78:947-958.

7. Curtiss, L. K. 1992. Cholesterol, apolipoprotein E, and immune cell function. In Nutrient Modulation of the Immune Response. S. Cunningham-Rundles, editor. Marcel Dekkar, Inc., New York. 169-181.

8. Boyles, J. K., R. E. Pitas, K. H. Weisgraber, R. W. Mahley, P. J. Gebicke- 
Haerter, M. J. Ignatius, and E. M. Shooter. 1986. Role for apolipoproteins-E and A-I in nerve degeneration and regeneration. Circulation. 74:11-195a. (Abstr.)

9. Gordon, V., T. L. Innerarity, and R. W. Mahley. 1983. Formation of cholesterol- and apoprotein E-enriched high density lipoproteins in vitro. J. Biol. Chem. 258:6202-6212.

10. Koo, C., T. L. Innerarity, and R. W. Mahley. 1985. Obligatory role of cholesterol and apolipoprotein $\mathrm{E}$ in the formation of large cholesterol-enriched and receptor-active high density lipoproteins. J. Biol. Chem. 260:11934-11943.

11. Linton, M. F., R. Gish, S. T. Hubl, E. Butler, C. Esquivel, W. I. Bry,

J. K. Boyles, M. R. Wardell, and S. G. Young. 1991. Phenotypes of apolipoprotein B and apolipoprotein E after liver transplantation. J. Clin. Invest. 88:270-281.

12. Plump, A. S., J. D. Smith, T. Hayek, K. Aalto-Setala, A. Walsh, J. G. Verstuyft, E. M. Rubin, and J. L. Breslow. 1992. Severe hypercholesterolemia and atherosclerosis in apolipoprotein E-deficient mice created by homologous recombination in ES cells. Cell. 71:343-353.

13. Zhang, S. H., R. L. Reddick, J. A. Piedrahita, and N. Maeda. 1992. Spontaneous hypercholesterolemia and arterial lesions in mice lacking apolipoprotein E. Science (Wash. DC). 258:468-471.

14. Beisiegel, U., W. Weber, G. Ihrke, J. Herz, and K. K. Stanley. 1989. LDL-receptor-related protein, LRP, is an apolipoprotein E-binding protein. Nature (Lond.). 341:162-164.

15. Chomczynski, P., and N. Sacchi. 1987. Single-step method of RNA isolation by acid guanidinium thiocyanate-phenol-chloroform extraction. Anal. Biochem. 162:156-159.

16. Palinski, W., V. A. Ord, A. S. Plump, J. L. Breslow, D. Steinberg, and J. L. Witztum. 1994. ApoE-deficient mice are a model of lipoprotein oxidation in atherogenesis. Demonstration of oxidation-specific epitopes in lesions and high titers of autoantibodies to malondialdehyde-lysine in serum. Arterioscler. Thromb. 14:605-616.

17. Piedrahita, J. A., S. H. Zhang, J. R. Hagaman, P. M. Oliver, and N. Maeda. 1992. Generation of mice carrying a mutant apolipoprotein $\mathrm{E}$ gene inactivated by gene targeting in embryonic stem cells. Proc. Natl. Acad. USA. 89:4471-4475.

18. Tsoi, M. S., S. Dobbs, S. Brkic, R. Ramberg, E. D. Thomas, and R. Storb. 1984. Cellular interactions in marrow-grafted patients. II. Normal monocyte antigen-presenting and defective T-cell-proliferative functions early after grafting and during chronic graft-versus-host disease. Transplantation (Baltimore). 37:556-561.

19. Gale, R. P., R. S. Sparkes, and D. W. Golde. 1978. Bone marrow origin of hepatic macrophages (Kupffer cells) in humans. Science (Wash. DC). 201:937-938.

20. Thomas, E. D., R. E. Ramberg, G. E. Sale, R. S. Sparkes, and D. W. Golde 1976. Direct evidence for a bone marrow origin of the alveolar macrophages in man. Science (Wash. DC) 192:1016-1018.

21. Goldeski, J. J., and J. D. Brain. 1972. The origin of alveolar macrophages in mouse radiation chimeras. J. Exp. Med. 136:630-643.

22. Shand, F. L., and E. B. Bell. 1972. Studies on the distribution of macrophages derived from rat bone marrow cells in xenogeneic radiation chimaeras. Immunology. 22:549-556.

23. van Furth, R. 1970. Origin and kinetics of monocytes and macrophages. Semin. Hematol. 7:125-141.

24. Virolainen, M. 1968. Hematopoietic origin of macrophages as studied by chromosome markers in mice. J. Exp. Med. 127:943-952.

25. Boak, J. L., G. H. Christie, W. L. Ford, and J. G. Howard. 1968. Pathways in the development of liver macrophages: alternative precursors contained in populations of lymphocytes and bone-marrow cells. Proc. R. Soc. Lond. Ser. Biol. Sci. 169:309-327.

26. Howard, J. G., J. L. Boak, and G. H. Christie. 1966. Further studies on the transformation of thoracic duct cells into liver macrophages. Ann. NY Acad. Sci. 129:327-339.

27. van Furth, R. 1989. Origin and turnover of monocytes and macrophages. Curr. Top. Pathol. 79:125-150.

28. Dawson, P. A., L. M. Lukaszewski, P. F. Ells, C. C. Malbon, and D. L. Williams. 1989. Quantification and regulation of apolipoprotein E expression in rat Kupffer cells. J. Lipid Res. 30:403-413.

29. Lee, S.-H., P. M. Starkey, and S. Gordon. 1983. Quantitative analysis of total macrophage content in adult mouse tissues. Immunochemical studies with monoclonal antibody F4/80. J. Exp. Med. 161:475-489.

30. Mahley, R. W., Z.-S. Ji, W. J. Brecht, R. D. Miranda, and D. He. 1994 Role of heparan sulfate proteoglycans and the LDL receptor-related protein in remnant lipoprotein metabolism. Ann. NY Acad. Sci. 737:39-52. 